boron Ions (Ionic Boron Hydrides)", by R. M. Adams and A. R. Siedle (134 pp., 624 references); "The Boranes or Boron Hydrides", by R. M. Adams (186 pp., 804 references); "Toxicology of Boron Compounds", by G. J. Leviriskas (45 pp., 182 references).

The book is all the more welcome because, of these topics, only two-elemental boron and the boron hydridescan be said to have been anything like adequately covered by earlier reviews, and oven these are now superseded by the present contributions, which are as comprehensive as one could wish. That so much ground was relatively untrodden is a far more important factor than any criticism one might wish to raise against the book on the grounds of heterogeneity. This latter characteristic may even be considered a virtue if it can be regarded as the outcome of sensitivity of the editor to former gaps in the fields surveyed. One result has certainly been the avoidance of overlap everywhere, except to a very minor extent between Chapters 2 and 3 . Perhaps the most serious aspect of the heterogeneity is the consideration that, whereas the book is obviously mainly intended for the pure chemist, the latter may justly complain that the first and final chapters have little significance for him. This is in part mitigated by the fact that, taken together, they constitute less than 10 per cent of the book. Certainly these reviews needed to be written-especially the final one, since information concerning the physiological action of boron compounds is not otherwise conveniontly accessible - but the wisdom of including them in the present book is questionable.

Deserving of special mention are the chapte: on boronoxygen chemistry and the chapters on hydroboron ions and boranes. That on boranes is sufficiently up to date to include reference to the recent isolations of $\mathrm{B}_{6} \mathrm{H}_{12}, \mathrm{~B}_{8} \mathrm{H}_{12}$ and $\mathrm{B}_{20} \mathrm{H}_{16}$, respectively. The woakest chapter is Chapter 2 , which is too brief and generalized and markedly below the high standard of the others.

To conclude, the appearance of this book is welcome and timely. It will be frequently consulted by inorganic chemists and is a 'must' for all serious boron chemists and those who are concerned with the teaching of advanced boron chemistry. The style is good and very readable throughout. Moreovor, the book is supplied with good formula and subject indexes. It is strongly recommended. L. H. LONG

\section{PROGRESS IN PETROLEUM CHEMISTRY AND REFINERY}

\section{Advances in Petroleum Chemistry and Refining}

Vol. 10. Edited by John J. McKetta, jun. Pp. xvi+571. (Now York and London: Interscience Publishers, a Division of John Wiley and Sons, 1965.) $210 s$.

TN my review of Volume 9 in the series Advances in Petroleum Chemistry and Refining, I wrote: "This series of volumes does, within obvious limitations, at least provide a useful means of leisure-study in the specialized subjects so far treated; to this extent it undoubtedly fills a gap in contemporary technical literature of scientific progress of petroleum technology which future volumes may woll gradually narrow" (Nature, 207, $230 ; 1965)$. That this gap will not now be bridged is made evident in the preface to Volume 10, where it is stated by the oditor, John J. MeKotta, jun., that this is the final volume of the series. The initial intent was an annual publication spread over the course of several years, during which " . . . the series of Advances will have touched upon all parts of the far-flung industry, and the set of volumes will assume the character of a reference book". Unfortunately, the co-editor, Dr. Kenneth A. Kobe, died in November 1958, not long after the series was initiated; this was followed by the death in April 1964 of a prominent member of the advisory board, Dr. Cecil L.
Brown; in these circumstances one can understand that even attaining the goal of ten volumes must have seemed an almost hopeless task, as the present editor remarks. So far, the volumes in the series have covered 96 chapters, nearly 5,600 pages, and have required the collaboration of 162 authors. It may be wondered whether another reason was instrumental in the decision to torminate the series at this juncture, namely restriction of sales, at least internationally, due to the relatively high cost of each volume, to which Volume 10 is no exception, and to which I have previously directed attention.

However, from a technical point of view, the quality and particularly the range of subjects discussed in this most recent issue are well up to the standards set by previous volumes in the series. There is a modern exposi. tion on "The Composition of Petroleum" by R. H. Hunt and M. J. O'Neal, jun. This is followed by a chapter on "Production and Distribution of Liquid Hydrogen", by C. R. Baker and L. C. Matsch. G. P. Hinds, jun., contributes an interesting paper on "Hydrogen Conservation in Petroleum Refining". "Hydrocarbon Gasification Processes" is the joint work of G. J. Van den Berg, W. R. Dammers, and L. W. ter Haar. Dewaxing of lubricating oils has long proceeded on conventional lines but the more recent reactions to the problem are admirably summarized by the chapter on "Modern Dewaxing Technology" by S. Marple, jun., and L. J. Landry. "In the near future petroleum may replace coal tar as the primary source of naphthalene..." is the theme of a dissertation on "Naphthalene from Petroleum", by H. D. Ballard, jun. On the more purely academic consideration of contem. porary petrochemical processes, there is the chapter on "Nonconventional Polymerization of Vinyl Monomers", by N. G. Gaylord, D. S. Hoffenberg, and H. F. Mark. Rather tangential, but none the less a welcome addition to the Advances in Petroleum Chemistry series, is the inclusion in this latest volume of a lengthy chapter on "Nitrogen Fertilizers", by S. Strolzoff and L. H. Cook: this is an excellent summary of the subject which deserves a wider audience than it may perchance attract. R. S. Egly and E. S. Starkman give us a general outline of the nature, production and uses of nitroparaffin fuels, while this volume, and hence the present series, is brought to a conclusion by consideration under the group heading "Mechanical Equipment" of "Engine Fuel Additives", by M. R. Barusch and J. H. Macpherson.

The high-level theoretical and practical purpose of this series and its execution during the years are unquestioned. The present editor and his advisory board deserve praise for their persistence, and sympathy in that this ambitions project has had to be abandoned 'midstream', so to spealk. It may later on be revived in another context; but I suggest that a far wider appeal would be satisfied by the inclusion of more authors of international fame (in four of the volumes, including this present one, taken at random, only five are other than American, out of a total of 65 contributors); and that the price bracket be favourably reassessed so that many other technologists, besides university and oil company libraries, may benefit from the wisdom this series purports to dispense. H. B. MiLner

\section{CHEMISTRY 1830 TO 1963}

A Hundred Years of Chemistry

By Prof. Alexander Findlay. Third edition revised by Trevor I. Williams. (University Paperbacks, No. 115.) Pp. 335. (London: Methuen and Co., Ltd., 1965.) 25s. net.

7 O quoto Dr. Williams's preface to the present edition of A Hundred Years of Chemistry: "It is hoped that this revised edition will serve the same purpose as its predecessors, to show that modern chemistry is firmly rooted in the past and to present the subject as the product of a process of continuous evolution". 